\title{
АКСИология кУЛЬтуPЫ
}

\section{AXIOLOGY OF CULTURE}

\author{
УдК 129 \\ DOI: 10.21209/1996-7853-2020-15-2-43-53
}

\author{
Надежда Дмитриевна Субботина, \\ Забайкальский государственный университет \\ (2. Чита, Россия), \\ e-mail:dialectica@yandex.ru
}

\section{Устарели ли понятия «сущность женщины» и «сущность мужчины»?}

В статье анализируются взгляды постмодернистов, которые критикуют эссенциалистский (сущностный) подход к причинам гендерных различий и противопоставляют ему подход, определяющий гендерные роли как социальный конструкт. Автор показывает ограниченность обоих подходов. Если первый признаёт лишь биологические, то второй - лишь социальные причины гендерных ролей мужчины и женщины. Если эссенциализм считает сущность человека неизменной, то постмодернизм абсолютизирует изменчивость, являясь разновидностью релятивизма. Делается вывод, что нужен третий подход, в основе которого лежит диалектика, учитывающая роль как естественных, так и социальных причин, взаимосвязанных друг с другом. По мнению автора статьи, следует различать биологическую, биосоциальную и социальную сущности человека. Биологическая сущность определяется ролью двух полов в продолжении и сохранении рода. На генетическом уровне мужской пол выполняет задачу развития, а женский - сохранения. Биосоциальная сущность человека выражается в том, что он имеет и природную, и социальную составляющие, поэтому она также остаётся неизменной. Если биологическая сущность у мужчины и женщины различна и согласно ей они являются противоположностями, то биосоциальная сущность у них едина. Социальная сущность человека проявляется в особенностях его социальных ролей, и она способна меняться. Общество на разных этапах своего развития обладает качественным разнообразием, что неизбежно сказывается на сущности живущих в данный период людей.

Ключевые слова: пол, гендер, мужчина, женщина, постмодернизм, эссенциализм, сексизм, натурализация и денатурализация, биологическая, биосоциальная и социальная сущность человека

\author{
Nadezhda D. Subbotina, \\ Transbaikal State University \\ (Chita, Russia), \\ e-mail: dialectica@yandex.ru
}

\section{Are the Concepts of "Essence of a Woman" and "Essence of a Man" Out of Date?}

The article analyzes the views of postmodernists who criticize the essentialist (essential) approach to the causes of gender differences and contrast it with an approach that defines gender roles as a social construct. The author shows the limitations of both approaches. If the first recognizes only biological, then the second only social reasons for the gender roles of men and women. If essentialism considers the essence of man to be unchanged, then postmodernism absolutizes variability, being a kind of relativism. It is concluded that the third approach is needed, which is based on dialectics, taking into account the role of both natural and social causes, interconnected with each other. According to the author of the article, it is necessary to distinguish between biological, biosocial and social nature of man. The biological essence is determined by the role of two sexes in the continuation and preservation of the genus. At the genetic level, the male sex fulfills the task of development, and the female - conservation. The biosocial essence of a person is expressed in the fact that he has both natural and social components, so it also remains unchanged. If the biological essence of a man and a woman is different and according to it, they are opposites, then the biosocial essence of them is one. The social essence of man is manifested in the features of his social roles, and it is able to change. Society at 
different stages of its development has a qualitative diversity, which inevitably affects the essence of people living in this period.

Keywords: sex, gender, man, woman, postmodernism, essentialism, sexism, naturalization and denaturation, biological, biosocial and social essence of man

Введение. Тема гендерных отличий мужчины и женщины - одна из самых популярных во всех гуманитарных науках в последние десятилетия, особенно в западных странах. Например, только в США и только в исторической науке, как отмечает Д. Б. Вершинина, количество исследователей, «специализирующихся в области женской и гендерной истории, согласно данным Американской исторической ассоциации за 1975-2005 гг., выросло более чем в восемь раз, а библиография по женской и гендерной истории только на английском языке настолько обширна, что сегодня не представляется возможным создание её исчерпывающей базы» [6, с. 172]. Можно представить, сколько публикаций возникло за 15 лет после этого подсчёта. Поэтому есть смысл анализировать лишь некоторые аспекты данной проблемы. В нашем случае - это проблема наличия или отсутствия сущности женщины и мужчины, соотношения гендера и пола.

В данном плане наиболее известны работы М. Фуко и Дж. Батлер. Лейтмотивом работ Фуко является идея «дискурсивного» характера сексуальности и социального контроля над сексуальностью [12]. Дж. Батлер, развивая эту идею, посчитала, что «додискурсивного», естественного пола вообще быть не может: «...возможно, конструкт, именуемый “полом", так же культурно обусловлен, как и гендер; на самом деле, возможно, он всегда уже был гендером, и, соответственно, разграничение между ними оказывается бессмысленным» [3, с. 307]. При этом следует отметить, что подобный подход не является единственным в западной литературе. Р. Д. Ашморе и А. Д. Севелл говорят о том, что среди учёных, по крайней мере, среди психологов, выработался консенсус, когда было решено понятие «пол» ("sex") использовать для обозначения биологических отличий мужчины и женщины, а гендер - для отличий, порождаемых социокультурными факторами [15]. Исследователи объясняют: «Основная причина, предложенная для этого терминологического описания, состоит в том, что без этого разделения и с учётом того, что слово “пол" чаще используется для обозначения всех различий между женщинами и мужчинами, люди могут сделать вывод, что все "различия полов" генетически даны, следовательно, не зависят от социальных условий, а также не изменчивы» [Там же]. То есть, признавая социальную основу понятия «гендер», они, тем не менее, от понятия «пол» не отказываются.

Исследователи, отождествляющие понятия «пол» и «гендер», гетеросексуальность называют «принудительной». По их мнению, практики принудительной сексуальности «должны выступать тем регулятивным опытом, который создаёт предпосылки для “идентичности” с опорой на сетки гендерных норм. <..> Таким образом, идентичность перестаёт быть имманентной спонтанному человеческому опыту, а сверяется по нормативному идеалу, поддерживаемому культурно интеллигибельными представлениями об идентичности» [11, c. 52]. Отметим, что идентичность здесь берётся в кавычки. Хотелось бы спросить, а насколько спонтанен человеческий опыт, может быть, он имеет естественные предпосылки?

На основе этих идей сформировалась так называемая «квир-теория». Термин «квир» не имеет однозначной интерпретации. А. Д. Номеровская пишет, что «в концепт "квир" заложена имманентная нестабильность и множественность значений» [Там же]. То есть, главная идея этого концепта - отмена разделения на норму и отклонение. О норме скажем далее.

В настоящее время в западных странах можно отметить бум исследований о причинах сексизма. Например, А. Клизинг исследовала влияние на степень сексизма и оценку сексизма теорий гендерных различий, которых придерживается человек. Одним группам участников эксперимента предлагали прочитать поддельную статью, которая якобы с научной точки зрения «доказывала» эссенциалистский (сущностный) подход, утверждающий, что гендерные роли зависят от биологических различий между полами и являются неизменными. А другой группе - псевдонаучную статью, «доказывающую» противоположную теорию, которая утверждает, что гендерные роли представляют собой социальный конструкт и не связаны с половыми различиями. После этого всем предлагали прочитать небольшие рассказы, в которых 
описывались ситуации проявления сексизма, и оценить поведение героев: насколько они сексистские и насколько такое поведение оправдано. А. Клизинг пишет, что её «исследование показало, что подверженность социальным конструкционистским объяснениям гендерных различий может привести к снижению одобрения отдельными лицами эссенциалистской гендерной теории и что менее эссенциалистская концептуализация пола как социальной категории повышает степень признания случаев несправедливого обращения по гендерному признаку как дискриминация» [16]. Не знаю, насколько необходимы подобные эксперименты для развития науки, но, на мой взгляд, они распространяют неверную идею о том, что возможны лишь два ответа на проблему гендера.

Методология и методика исследования. В основе методологии данной статьи лежат сравнительный и диалектические методы. Автор сравнивает подход, получивший в последние годы название «эссенциалистский» (сущностный), и гендерный подход к исследованию причин гендерных различий. Первый признаёт лишь биологические, а второй - лишь социальные причины гендерных ролей мужчины и женщины. Использование диалектического метода позволило отметить ограниченность обоих подходов, показать, что нужен третий, в основе которого лежит диалектика, учитывающая роль как естественных, так и социальных причин, взаимосвязанных друг с другом. Автор опирается также на собственную концепцию соотношения естественного и социального в обществе и человеке.

Результаты исследования и их обсуждение. Е. Б. Хитрук критикует, как она называет «классический философский дискурс» понимания половой дихотомии. По её мнению, классическая философия «последовательно натурализует, то есть представляет как необходимые аспекты бытия, следующие значимые характеристики половой дихотомии: 1. Эссенциализм - представление о том, что в бытии укоренены некие мужская и женская сущности. 2. Поляризация полов - представление о том, что эти сущности противоположны друг другу. 3. Субординация полов - представление о том, что мужской пол обладает онтологическим, гносеологическим, аксиологическим и другими преимуществами по отношению к женскому полу» [14, с. 101-102]. Отсюда основная задача данной статьи - попытка ответа на вопрос: «Имеет ли смысл говорить о женской и мужской сущности?»

Начну с того, что, согласно диалектике, любой материальный или идеальный предмет имеет свою сущность. На мой взгляд, можно говорить среди прочего о наличии женской и мужской сущности. Эти сущности действительно противоположны друг другу, имея при этом общую основу. Каждая из противоположностей - человек, поэтому общих черт у них больше, чем имеющихся морфологических и функциональных отличий. При этом морфологические черты (первичные и вторичные половые признаки) обусловлены биологическим предназначением полов. Два пола выполняют две биологические функции - сохранение генофонда (преимущественно женский пол) и развитие (преимущественно мужской пол) [7; 8]. И обе эти функции естественные (природные). Они перешли к нам от наших животных предков и никуда не делись в настоящее время, несмотря на поразительное развитие всех сторон общества.

Представление о превосходстве мужского пола, многие века господствовавшее в обществе, также имеет естественное происхождение и обусловлено выполняемыми им функциями. Надо учитывать, что превосходство того или иного субъекта можно обнаружить тогда, когда они занимаются одним и тем же видом деятельности, благодаря чему их можно сравнивать по степени успешности. В обществе, когда было преодолено жёсткое разделение ролей, женщины начали пробовать себя в делах, традиционно принадлежащих мужчинам, а мужчины (реже, но всё же, бывает) - заниматься традиционно женскими делами. И вначале, конечно, каждая из сторон проигрывала «на чужом поле». Не только из-за нехватки опыта, но и потому, что морфологически не была приспособлена к такой деятельности. Однако, как писал В. А. Геодакян, новые виды деятельности лучше получаются у мужчин. Они более креативны, более остроумны, хотя это средний показатель, и есть немало женщин, более умных, чем средний мужчина, более сильных физически, более высоких и т. д. [8]. Так как мужчина и женщина - два пола одного вида, процессы мышления у них организованы одинаково ${ }^{1}$. Поскольку для решения логических задач физическая сила не нужна, постольку женщины оказались способ-

\footnotetext{
1 Пресловутой «женской логики» не существует.
} 
ны к «чисто» мужским делам, а в чём-то и превосходить их.

Рассмотрим проблему сущности женщины более подробно.

Дж. Батлер обращает внимание на то, что в современной философиии представление о женщине как субъекте сильно разнится. Исследователи вкладывают в данное понятие разные смыслы, и это не только традиционное представление о женщине как домохозяйке. Борьба за определение сущности женщины идёт даже внутри течения феминизма. Взгляды одних авторов подвергаются критике со стороны других. Батлер замечает: «В начале 80-х феминистское “Мы" подверглось справедливым атакам цветных женщин, утверждавшим, что “МЫ" всегда белое, и что это "МЫ", предназначавшееся для солидаризации движения, само становится источником болезненной фракционализации. Попытка характеризовать специфику женского через обращение к материнству, биологическому или социальному, производит такую же фракционализацию или даже отречение от феминизма в целом. Ибо безусловно не все женщины суть матери; некоторые не могут ими быть...» [5, с. 250]. Она утверждает, что вообще любая попытка дать универсальное определение категории женщин приведёт к фракционализации, результат такого определения идентичности не может быть основанием для феминистского движения.

Да, действительно, если отказаться от очевидного восприятия морфологических характеристик женщины, которые часто не учитывают фреминистки, то возникают подобные трудности. На мой взгляд, у женщины есть чёткая определённость - наличие в её организме репродуктивной системы, предназначенной для рождения детей. Она может рожать или не рожать, может хотеть или не хотеть детей ${ }^{1}$, её репродуктивные органы могут находиться на стадии формирования, быть готовыми к деторождению или уже по возрасту утратившими подобные функции, но она остаётся женщиной по половому признаку. Часть женских органов может быть даже удалённой посредством операций, но остальная часть системы сохраняется, вырабатывая женские гормоны.

Мне могут возразить, что это не социальная, а биологическая определённость. Однако этого достаточно для идентификации и самоидентификации, для того чтобы

1 Даже если женщина не стремится к материнству, её биология неизбежно оказывает воздействие на её быт, мысли и поведение. назвать субъекта или объекта исследования женщиной. Биологическая сущность и мужчины, и женщины определяется ролью двух полов в продолжении рода.

Конечно, любой человек, субъект, личность не сводится к организму. Всё, что составляет сущность индивида, если не учитывать его половую принадлежность, позволяет ему идентифицировать себя, к примеру, как русского (русскую), как учителя, гражданина (гражданку), как соседа (соседку). И так далее. Такое основание дают её социальные роли. Но также субъект-женщина может идентифицировать себя как мать, жена, дочь, сестра, подруга, возлюбленная. Такие роли можно назвать биосоциальными². Любая из перечисленных во втором списке ролей возможна только в том случае, если этот субъект женщина. Конечно, все эти роли шире половой принадлежности, в их основании лежат сложнейшие социальные функции.

Таким образом, социальные и биосоциальные роли женщины могут меняться по социальным или естественным, в том числе возрастным причинам, чаще всего они сочетаются друг с другом. Но биологическая сущность женщины остаётся неизменной от рождения до смерти. И лишь в тех случаях, которые связаны с её репродуктивной фрункцией, мы обращаемся к её сущности как женщины.

Общаясь с женщиной, в большинстве случаев на первое место мы (за исключением крайних, открытых сексистов) ставим её социальные или биосоциальные роли. В первом случае в настоящее время биологические особенности её организма должны быть исключены из процедуры общения. Хотя и здесь возможны исключения. Ясно, что с физически трудной работой женщины не смогут справиться. Например, на космической станции для женщин-космонавтов должны быть специальные условия. В случае общения с женщиной, которая в данный момент осуществляет свои биосоциальные роли (ранее названные роли матери, возлюбленной и т. д.) должны учитываться её биологическая сущность и социальная составляющая её личности.

Однако женщина одновременно и человек, и как человек, она имеет не только биологическую, но и биосоциальную сущность. Составная «био-» в данном опре-

2 Хочу обратить внимание на что, что не надо отождествлять биосоциальные роли женщины и мужчины с биосоциальной сущностью человека, о которой будет сказано далее. 
делении не сводится ни у женщины, ни у мужчины к репродуктивной функции, хотя и включает её. Человек - это феномен реальности, который имеет биологическую морфологию, физиологию и психологию1, и одновременно социальные черты. Он обладает сознанием, самосознанием, развитым мышлением, нравственностью и способностью к творческому труду. Если биологическая сущность у мужчины и женщины различна и согласно ей эти два пола выступают как две противоположности, то биосоциальная сущность у них едина. Отметим, что не следует отождествлять биосоциальную сущность и биосоциальные роли человека, о которых говорилось ранее и которые различны для мужчины и женщины. Более подробно о биосоциальной сущности человека говорить не будем, поскольку о ней написано много.

Очень популярны высказывания феминистов, и в целом социальных конструктивистов, обращающие внимание на то, что общество навязывает женщинам и мужчинам гендерные роли, которые те вынуждены исполнять, чтобы не подвергаться осуждению окружающих. Например, М. Киммел цитирует американского биолога Рут Хаббард: «Если общество одевает половину своих детей в короткие юбки и не велит им двигаться так, чтобы были видны трусики, а другую половину - в джинсы и комбинезон, поддерживая их желание лазать на деревья, играть в мяч и другие активные дворовые игры; если позже, в юности, детей, которые носили брюки, убеждают, что "растущему мальчишке надо много есть", в то время как дети в юбках предупреждены, что надо следить за весом и не толстеть; если половина в джинсах бегает в кроссовках или ботинках, в то время как половина в юбках ковыляет на шпильках, то эти две группы людей будут отличаться не только социально, но и биологически» [цит. по: 9, c. 78]. И это действительно так. Всё это примеры воздействия социального на биологическое, приводящее к некоторому искажению («корректировке», согласно господствующим представлениям) биологического, но не отменяющего биологической сущности пола. Биологическая (морфологическая) сущность может изменяться (но не отрицаться) только при операциях по

1 Вообще, конечно, понятия «морфология», «физиология» и «психология» являются названиями наук, но их традиционно используют и для названия изучаемых этими науками объектов. Правильнее было бы говорить «морфика», «физика» и «психика». смене пола, очень редким, но по большей части исправляющим «ошибки природы», когда естественная психология не сочетается, или противостоит естественной физиологии и анатомии. Но и это не отменяет естественности (несоциальности) пола.

Кроме того, не надо впадать в крайности, утверждать, что все особенности воспитания мальчиков и девочек лишние, а потому им нужны одинаковые методы воспитания. Есть сферы, где требуются особые способы воспитания. Для девочек это необходимо тогда, когда их готовят к будущему материнству. Предвосхищая возражения некоторых феминисток и представителей течения чайлд-фри, уточню - возможному материнству.

Развивая мысль о том, что гендер исключительно навязан человеку господствующими культурными представлениями, Дж. Батлер утверждает: «Не только не существует причинно-следственной связи между полом и гендером, но само слово “пол" является неправильным употреблением термина, и биологическая действительность, которую мы называем полом, сама есть исторический конструкт и на самом деле является политической категорией» [4, с. 302]. Е. Б. Хитрук на основании этого высказывания делает вывод: «Поэтому на самом деле мы имеем дело не с "натуральным полом", а с "натурализацией пола”, которая представляет собой лишь один из способов навязывания гендерной идентичности» $[14$, с. 145-146].

Здесь, на мой взгляд, авторы переходят границу меры: описывая навязывание обществом гендерных ролей (что действительно существует), они приходят к отрицанию биологической сущности пола.

Хитрук описывает различные стратегии «денатурализации» обоих полов. Рассмотрим кратко стратегии «денатурализации» женского пола. К таким стратегиям она относит «когнитивную», которая «разоблачает» традиционные установки о половых различиях, включающие в себя андроцентризм, биологический эссенциализм, гендерную поляризацию, обосновывающие и конструирующие тем самым социальное неравенство [13, с. 22]. На мой же взгляд, эти установки не конструируют неравенство, которое и без них реально существует, а в первую очередь оправдывают его теоретически. И уже во вторую очередь сохраняют и поддерживают его. Неравенство имеет тысячелетнюю традицию и 
естественную предпосылку, выражающуюся в том, что мы произошли от животных, в которых самцы играли ведущую роль.

Следующая стратегия в списке Хитрук - «концепция гендерного пересечения». Утверждается, что в её рамках «формирование гендерной идентичности рассматривается не в контексте проявления и осознания фризиологической сущности, а в контексте свободы выбора, как одного из самых важных и необходимых атрибутов человеческого существования» [14, с. 24]. Здесь следует уточнить, что традиционно под гендерным пересечением понимается пересечение гендерных ролей с ролями, обусловленными принадлежностью к расе, этносу, социальному классу и прочим большим или меньшим группам. Например, C. C. Бабаян пишет: «Гендерные стереотипы соотносятся с реальной стратификацией общества и пересекаются с этническими особенностями, возрастом, образованием, социальным статусом, условиями жизни и т. д.» [1]. С точки зрения Хитрук, пересечение гендерных ролей - это их смена на противоположные роли, которые человек свободен выбирать сам.

В качестве примера такой свободы выбора Е. Б. Хитрук приводит историю Дейдры Макклоски, которая, будучи от рождения мужчиной, ощущала себя женщиной и в 52 года стала ею [13]. То есть, Макклоски выбрала гендер по своему желанию. Думается, всё же, что в основе решения сменить пол в данном случае лежит не гендерная, а половая принадлежность, как понимал её этот индивид. Ведь авторы данного направления говорят, что гендер навязан обществом, а когда человек ставит не задачу выбрать гендер по своему желанию, что можно сделать (и часто делается) без смены пола, а сменить именно биологический пол, он тем самым ставит свой желанный пол на первое место по отношению к гендерным ролям. Конечно, можно порадоваться тому, что Дейдра Макклоски смогла осуществить своё желание в наше, достаточно цивилизованное, но во многом ещё консервативное время.

Здесь следует обратиться к некоторым другим понятиям, вошедшим в современную научную литературу. Понятие «транссексуализм» (М. Хиршфельд, Д. Коулдвелл, Г. Бенджамин) отражает психологическое ощущение принадлежности к другому полу. Понятия «гендер» ${ }^{1}$ и «гендерная роль»,

1 В данном случае, на мой взгляд, больше подходит понятие «пол» (sex). введённые Дж. Мани, призваны разграничить принадлежность к биологическому полу и психологическое ощущение принадлежности к полу. Позднее Мани ввёл ещё одно разграничение, добавив термин «гендерная идентичность»: «Гендерная идентичность является личным ощущением гендерной роли, и гендерная роль является публичным выражением гендерной идентичности» [17]. Ещё одно распространённое понятие «гендерная дисфория» обозначает неприятие данного от рождения тела (пола). Я. Кирей-Ситникова обращает внимание на то, что это понятие в 5-й версии «Диагностического и статистического руководства по психическим расстройствам (DSM)» признаётся патологией. Она же считает, что это всего лишь «гендерная вариативность» [10, с. 14-15]. Поэтому исследователь уточняет, что в своей монографии она отказывается от медицинской терминологии и оставляет лишь понятие «трансгендерность». В самом общем понимании трансгендерность - это несоответствие между биологическим полом и гендерной идентичностью. Наверное, нужно добавить, что в основе этого несоответствия лежит несоответствие между морфологией пола и его психологическим осознанием, а причиной этого несоответствия являются некоторые естественные особенности человека и, возможно, в ряде случаев внушённые со стороны представления.

Я. Кирей-Ситникова пишет, что в современном обществе цисгендерность считается нормой, а трансгендерность - отклонением от нормы. Всё это тяжело переносится людьми, имеющими трансгендерные ощущения: «Наличие циснормативных убеждений... широко встречается у трансгендерных людей с вытекающей из наличия таких убеждений внутренней трансфобией» [Там же, с. 15]. Такую циснормативность, по её мнению, следует искоренять. На мой же взгляд, искоренять надо не циснормативность, а различные проявления ксенофобии, в том числе, ксенофробию по отношению к трансгендерам, и одновременно помогать трансгендерам преодолевать свою «Внутреннюю трансфобию».

Хочется сказать несколько слов в защиту понятия «норма», которое всё больше размывается как побочное следствие борьбы за права различных групп населения, в чём-то отличных от основной массы людей. Борьба за равные права - это прогрессив- 
ное движение современной цивилизации, которое надо всячески приветствовать. Но расширение представлений о сексуальной норме, посредством включения в неё гомосексуалов и трансгендеров, неизбежно, согласно диалектическому закону перехода количественных изменений в качественные, приведёт к уничтожению самого понятия «норма». А оно человечеству пока нужно. Вспомним, хотя бы, нормы права, нормы нравственности и т. п. В медицине также есть чёткие договорённости, какие параметры (температуры, давления и прочих показаний) считать нормальными («от и до»), а какие - нарушением нормы. Хотя цифры этих параметров могут меняться, но представление о наличии нормы и её нарушений остаются неизменными.

Я не случайно в предыдущем абзаце уточнила, что речь здесь идёт лишь о сексуальной норме. Думаю, что практически каждый человек, имея большинство нормальных характеристик, обладает различными отклонениями. Например, плохо видит или слышит, имеет инвалидность, отклонения в весе и росте, психические особенности и прочее. И всё это, за исключением антиобщественного поведения, не должно вызывать осуждения и быть основанием для дискриминации. Более того, некоторые отклонения от нормы могут приветствоваться обществом. Например, необычные способности детей-вундеркиндов, повышенная переносимость вредных воздействий окружающей среды и т. д.

Да, действительно, мы всегда сверяем своё поведение с принятыми нормами, потому что живём в обществе, которое иногда называют «человеческим общежитием». Давайте задумаемся над тем, почему об одних собственных отклонениях от норм мы спокойно говорим окружающим, иногда даже с охотой, рассчитывая на сочувствие или помощь, а о других предпочитаем молчать. Имеются в виду психические заболевания и сексуальные отклонения. У меня есть некоторые предположения о причинах этого. Думаю, что к психическим отклонениям люди относятся настороженно потому, что обладатели ряда таких отклонений способны к девиантному поведению, что представляет некоторую опасность для общественного порядка. Хотя абсолютное большинство преступлений совершаются людьми с нормальной психикой. Что касается сексуальных отклонений, то одна из причин, на мой взгляд, заключается в том, что в обществе на протяжении тысячелетий существовало табу на открытое обсуждение всего, что касается секса. Мы видим, что в последнее время это табу всё больше ослабевает, особенно на Западе, где многие известные люди совершили каминг-аут. В скором времени так будет и у нас. Но есть и другая, более глубокая причина негативного отношения к гомосексуалам. Дело в том, что в основе такого отношения лежит неприязнь к ним на инстинктивном уровне, которую нам привила природа, «ставящая цель» сохранения у человека репродуктивной функции. Изменить такое отношение можно только с помощью пропаганды толерантности и воспитания.

Что касается Дейдры Макклоски, которая в 52 года стала женщиной, то это, на мой взгляд, не «вопреки биологической данности», как считает Е. Б. Хитрук [13], а именно благодаря ей. Он не сам придумал, что ему хочется быть женщиной, а что-то (учёные биологи, медики и психологи лучше это объяснят) толкало его на такой шаг. Это трагедия человека, которому приходится противостоять одновременно и биологической природе, «наградившей» человека мужским телом и женской психикой, и обществу, которое в большинстве своём не принимает права на смену пола, считает это недопустимой аномалией. Это и в самом деле биологическая аномалия, но в социальной действительности человек имеет право на смену пола, а общество не должно его за это осуждать. Однако такие ситуации - крайняя редкость и человек уже в детском возрасте сам способен осознать психологическое несоответствие с биологическим полом, если оно возникнет. При условии, если он растёт в семье, где приняты доверительные отношения, он поделится этим с родителями, которые проконсультируются с психологами, врачами и примут решение, как ему помочь.

Когда же на уроках в школе начинают продвигать идею о том, что человек сам должен выбирать свой пол (сведения о таком есть), то это может нанести огромный вред детям, которые до этого даже не задумывались о своей половой принадлежности, понимая (совершенно правильно), что это само собой разумеется. Теперь же они могут начать сомневаться, кому-то покажется, что он находится в неправильном теле и т. д. Может дойти до того, что человек поймёт необоснованность своих предположений, когда уже хирургически сменит 
пол, а вернуться назад уже будет нельзя. То есть, тему половой принадлежности ребёнка следует обсуждать только в том случае, если сам ребёнок начнёт реально в ней сомневаться.

На мой взгляд, само по себе выделение только двух подходов к проблемам пола неверно. Например, Е. Б. Хитрук называет две парадигмы: «классическую метафизическую», порождающую эссенциализм и натурализацию пола, и постметафизическую, способную осуществить его денатурализацию [14, с. 19 и далее]. Это и есть дуализм, который Хитрук критикует, когда говорит о бинарных оппозициях как об устаревшем подходе классической философии [Там же, с. 273]. Думается всё же, что диалектика (если не понимать её упрощённо, как только признание этих оппозиций) никогда не устареет. Естественное (синонимы: «природное», «натуральное») и социальное являются диалектическими противоположностями, которые не только исключают друг друга, но и взаимопроникают друг в друга и взаимодополняют друг друга. Следовательно, логично предположить, что возможен (более того, необходим) третий подход, который учитывает как естественные, так и социальные составляющие половой дифференциации.

Гендерные роли тесно связаны и с половой принадлежностью, и с социальными практиками. По сути, они и есть биосоциальные роли, о которых я упоминала ранее. В настоящее время общество часто продолжает предписывать женщине быть послушной, покладистой, не выходить за рамки домашних обязанностей. Частично это объясняется тем, что культурные стереотипы очень прочны, частично тем, что мужчины имеют фризическое превосходство, чтобы подчинить женщину и иметь возможность наказать за неподчинение. То есть, такие требования к женщине обоснованы не безликим социумом, а биологическими особенностями мужчины и женщины. Далее - отсутствие необходимости находиться рядом с малыми детьми - позволяет мужчинам быть более успешными в общественной жизни. Всё это согласуется с естественной функцией мужского пола способствовать развитию. Всё названное является биологическим основанием гендерных ролей, к которым общество добавляет различные требования «по вкусу».

Е.Б. Хитрук пишет, что в контексте постфеминистской философии быть жен- щиной, «значит - быть сконструированным той или иной исторически сформированной дискурсивностью, как то естественное начало, которое в определённой степени обеспечивает жизнеспособность данной формы дискурса» [14, с. 147]. То есть, получается, что женщина не имеет ничего своего, устойчивого, она - просто конструкция, созданная общественными отношениями. Категорически с этим не согласна. Женщина может полностью добровольно или вынужденно отказаться от выполнения функций, предназначенных ей биологией. Она может не рожать, не воспитывать детей, не заниматься сексом. При этом она не становится мужчиной или неким «просто человеком» без каких-либо половых признаков. Биологически она остаётся женщиной, что, несомненно, будет оказывать влияние на её социальное поведение.

Так же, как и в отношении женщин, постмодернисты отмечают сконструированность мужского идеала и обоснованность им мужских гендерных ролей. Что порождает сложности для тех мужчин, которые в чём-то этому идеалу не соответствуют. Э. Бадентэр пишет: «Мужчина представляет собой рукотворный продукт, отличающийся от творения природы, и как таковой он постоянно подвергается риску быть признанным продуктом с изъяном, подобно браку производства, с дефектом в мужском оснащении. Короче, мужчина может оказаться несостоявшимся» [2, с. 13-14]. Соглашаясь с тем, что идеал мужчины как смелого, успешного, почти лишённого эмоций и т. д. является социальным конструктом и продолжает уже без необходимых оснований навязываться со стороны общества и мужчинам, и женщинам, хочу уточнить. По моему мнению, социально сконструированный идеал «настоящей мужественности» имеет и естественные, и социальные предпосылки. Идеал мужественности (нравственная норма) сформирован многовековым опытом человечества. Он создавался как отражение поведения мужчин, подчиняющихся естественно возникшей норме защиты своей группы. Некоторые мужчины совершают подвиги, так как в генетической программе человека есть инстинкт коллективного самосохранения. Если бы его не было, человечество не дожило бы до эпохи цивилизации. Однако так не могут вести себя все мужчины, и не только потому, что у многих преобладает инстинкт личного самосохранения. Обществу нужны разные 
мужчины: и те, кто способен вступить в бой, совершить подвиг, и те, кто может создать музыкальное произведение, сделать научное открытие. Но общество продолжает осуждать «не мужественное» поведение. Здесь работает социальный конструкт, основанный на традиции. В настоящее время, если нет чрезвычайных ситуаций и войн, от мужчины уже не требуется совершать подвиги. Пришло осознание того, что мужчина имеет право выражать открыто свои эмоции, быть «мягким», покладистым. Поэтому в настоящее время возникает новый, менее однозначный, социальный конструкт категории «мужчина».

На воспитание мальчиков, как и девочек, влияют одновременно и биологические особенности их тела, и гендерные представления, господствующие в определённой эпохе. К сожалению, мы пока живём в обществе, когда будущий мужчина должен быть готов к возможной военной службе, что накладывает на его воспитание некоторые особенности. Конечно, убеждение, что настоящий мужчина - это обязательно готовый солдат, характерно для милитаристски настроенного общества. Оно не учитывает того, что мужчины от рождения или благодаря воспитанию разные, имеют различные ценности и цели, и так же, как не все женщины желают рожать, так и многие мужчины, которых становится всё больше, не желают воевать и убивать себе подобных. Вместо этого они предпочитают создавать что-либо новое, или просто жить, занимаясь мирным трудом. Разумеется, в случае внешней опасности, вероятность которой в современном мире ещё велика, такие мужчины будут вынуждены воевать.

Выводы. Итак, надо различать биологическую, биосоциальную и социальную сущности человека. Биологическая сущность остаётся неизменной и будет такой ещё долго, если только общество не вздумает вмешаться на генетическом уровне в морфологию, физиологию и глубинную психологию человека.

Биосоциальная сущность выражается только в том, что человек имеет и природную, и социальную составляющие, поэтому она также остаётся неизменной. Данный вывод не изменится, даже если будут реально созданы киборги, так как они будут обладать своей, иной сущностью.

Социальная сущность человека проявляется в особенностях его социальных ролей, и она способна меняться, так как об- щество на разных этапах своего развития и в различных регионах обладает качественным разнообразием, что неизбежно сказывается на сущности живущих в данный период и в данном регионе людей.

Взаимосвязь биологической и социальной сущности человека проявляется в том, что его природная и социальная стороны взаимодействуют между собой. Социальное держит биологию под контролем, подавляет нежелательные для общества проявления психики человека, «ремонтирует» поломки биологического тела. Но в то же время, социальное постоянно приспосабливается к биологическому. Например, одежду шьют такую, чтобы подходила к телу. Соглашаясь с тем, что брюки и удобная обувь для мальчиков, а юбки и обувь на шпильках для девочек навязаны обществом, вспомним, что бельё для них было и будет разным.

Можно сказать, что «денатурализация» в ином, отличном от постмодернистского подхода смысле - это процесс подчинения естественного социальному: лишение естественных морфологических органов и генетических программ своих устойчивых функций; возникновение новых, социальных, изменчивых функций. Происходит это из-за расширения в жизни людей роли мышления и сознания, которые уже не ограничиваются созданием стратегий элементарного выживания, решают задачи развития и совершенствования общества. Однако такая денатурализация не может быть полной, она всегда частичная.

Сторонникипостмодернистского (более конкретно - постфеминистского) направления правы во многих своих утверждениях, но учитывают лишь одну из составляющих человека - его зависимость от гендерных представлений на каждом определённом этапе существования. Это мне напоминает советские учебники по философии, в которых говорилось, что нет общества вообще, есть конкретные формации. Да, конечно, абстрактного «общества вообще» не существует, но во всех конкретных крупных объединениях людей есть сходные черты, которые и позволяют называть их обществом. Так же и с человеком. Утверждение, что нет мужчин и женщин «вообще», а есть лишь представители своей эпохи с навязанными им гендерными ролями, также не учитывает, что в каждом мужчине и в каждой женщине на каждой исторической ступени есть не только особенное и единичное, но 
и общее. При этом отнесение к общему и особенному относительно. Общими можно считать наличие общих для мужчины и для женщины признаков пола. Это чисто биологическая составляющая сущности мужчины и женщины. Можно обнаружить социальные сущностные черты мужчин и женщин определённой эпохи или определённого этноса и т. д. Если эссенциализм, который критикуют постмодернисты, считает сущность человека неизменной, то сам постмодернизм абсолютизирует изменчивость, являясь разновидностью релятивизма. И лишь диалектика единичного и общего, устойчивого и изменчивого, естественного и социального может представить целостную картину сущности мужчины и женщины, человека в целом.

\section{Список литературы}

1. Бабаян С. С. Гендер и межкультурная коммуникация: потенциальные поля пересечения // Вестник Костромского государственного университета им. Н. А. Некрасова. 2009. № 15. С. 285-289. $304 \mathrm{c}$.

2. Бадентэр Э. Мужская сущность / пер. с фр. И. Ю. Крупичевой, Е. Б. Шевченко. М.: Новости, 1995.

3. Батлер Дж. Гендерное беспокойство // Антология гендерной теории / сост. и коммент. Е. И. Гаповой и А. Р. Усмановой. Минск: Пропилеи, 2000. С. 297-346.

4. Батлер Дж. Присвоение телом гендера: философский вклад Симоны де Бовуар // Женщины, познание и реальность: Исследования по феминистской философии: пер. с англ. / сост. Э. Гарри, М. Пирсел. М.: РОССПЭН, 2005. С. 292-303.

5. Батлер Дж. Случайно сложившиеся основания: феминизм и вопрос о «постмодернизме» // Введение в гендерные исследования / под ред. С. В. Жеребкина. Харьков: ХЦГИ; СПб.: Алетейя, 2001. Ч. 2. С. 235-257.

6. Вершинина Д. Б. Гендерные аспекты истории Запада: основные дискуссионные поля. Текст: электронный // Вестник Пермского университета. 2017. Вып. 4. URL: https://www.cyberleninka.ru/article/n/ gendernye-aspekty-istorii-zapada-osnovnye-diskussionnye-polya (дата обращения: 05.01.2020).

7. Геодакян В. А. Половой диморфизм и «отцовский эффект» // Журнал общей биологии. 1981. № 5. С. 657-668.

8. Геодакян В. А. Роль полов в передаче и преобразовании генетической информации // Проблемы передачи информации: в 2 т. Т. 1. М.: Изд-во РАН, 1965. С. 105-112.

9. Киммел М. Гендерное общество: пер. с англ. М.: РОССПЭН, 2006. 464 с.

10. Кирей-Ситникова Я. Трансгендерность и трансфеминизм. М.: Саламандра, 2015. 200 с.

11. Номеровская А. Д. Понятие нормативности в современных теориях гендерной идентичности. Текст: электронный // Парадигма: философско-культурологический альманах. URL: https://www. cyberleninka.ru/article/n/ponyatie-normativnosti-v-sovremennyh-teoriyah-gendernoy-identichnosti (дата обращения: 05.01.2020).

12. Фуко М. Использование удовольствий. История сексуальности. СПб.: Акад. Проект, 2004. Т. 2. $432 \mathrm{c}$.

13. Хитрук Е. Б. Гендерное пересечение как фактор денатурализации половых различий в теории Дейдры Макклоски. URL: https://www.researchgate.net/publication/324600302_Gendernoe_peresecenie_ kak_faktor_denaturalizacii_polovyh_razlicij_v_teorii_Dejdry_Makkloski (дата обращения: 15.01.2020).

14. Хитрук Е. Б. Стратегии денатурализации категорий «мужское» и «женское» в современной философии: дис ... д-ра филос. наук: 09.00.11. Томск, 2018. 375 с.

15. Ashmore R. D., Sewell A. D. Sex/Gender and the Individual. URL: https://www.link.springer.com/ chapter/10.1007 \%2F978-1-4419-8580-4_16 (дата обращения: 05.01.2020). Текст: электронный.

16. Klysing A. Exposure to Scientific Explanations for Gender Differences Influences Individuals' Personal Theories of Gender and Their Evaluations of a Discriminatory Situation. Текст: электронный // Sex Roles. Volume 82, Is. 5-6. Pp. 253-265. URL: https://www.link.springer.com/article/10.1007/s11199-019-01060-w (дата обращения: 05.02.2020).

17. Money J. and Ehrhardt, A. A. Man and woman, boy and girl: Differentiation and dimorphism of gender identity from conception to maturity. Baltimore: Johns Hopkins U. Press, 1972. 311 p.

Статья поступила в редакцию 08.02.2020; принята к публикации 28.02.2020

\section{Сведения об авторе}

Субботина Надежда Дмитриевна, доктор философских наук, профессор, Забайкальский государственный университет; 672039, Россия, г. Чита, ул. Александро-Заводская, 30; e-mail: dialectica@ yandex.ru; https://orcid.org/0000-0003-3251-4076.

\section{Библиографическое описание статьи}

Субботина Н. Д. Устарели ли понятия «сущность женщины» и «сущность мужчины»? // Гуманитарный вектор. 2020. Т. 15, № 2. C. 43-53. DOI: 10.21209/1996-7853-2020-15-2-43-53. 


\section{References}

1. Babayan, S. S. Gender and intercultural communication: potential intersection fields. Bulletin of KSU named after N. A. Nekrasov. no. 15, pp. 285-289, 2009. (In Rus.)

2. Badenter, E. Men's Essence. Transl. from French by I. Yu. Krupichevoi, E. B. Shevchenko. M: Izd-vo "Novosti". 1995. (In Rus.)

3. Batler, J. Gender Concern. Anthology of gender theory / comp. and comment. E. I. Gapova and A. R. Usmanova. Minsk: Propilei, 2000: 297-346. (In Rus.)

4. Batler, J. The appropriation of gender by the body: the philosophical contribution of Simone de Beauvoir. Women, cognition and reality: Studies on feminist philosophy.Comp. E. Harry, M. Piersel; trans. from English. M: ROSSPE'N, 2005: 292-303. (In Rus.)

5. Batler, J. Accidentally Foundations: Feminism and the Question of "Postmodernism". Introduction to Gender Studies. Part II / Ed. S. V. Zherebkin. Xar`kov: XCzGI, 2001; SPb: Aletejya, 2001: 235-257. (In Rus.)

6. Vershinina, D. B. Gender aspects of the history of the West: the main discussion fields. Bulletin of Perm University, no.4, 2017. Web. 05.01.2020. https://www.cyberleninka.ru/article/n/gendernye-aspektyistorii-zapada-osnovnye-diskussionnye-polya. (In Rus.)

7. Geodakyan, V. A. Sexual dimorphism and the "paternal effect" // Journal of General Biology, no. 5, pp. 657-668, 1981. (In Rus.)

8. Geodakyan, V. A. The role of sexes in the transfer and transformation of genetic information. Problems of information transfer: in 2 v. V. 1. M. Izdatel'stvo RAN, 1965: 105-112. (In Rus.)

9. Kimme,I M. Gender Society / trans. from English. M: ROSSPE'N, 2006. (In Rus.)

10. Kirei-Sitnikova, Ya. Transgender and Transfeminism. M: Salamandra, 2015. (In Rus.)

11. Nomerovskaya, A. D. The concept of normativity in modern theories of gender identity. Paradigm: philosophical and cultural almanac. Web. 05.01.2020. https://www.cyberleninka.ru/article/n/ponyatienormativnosti-v-sovremennyh-teoriyah-gendernoy-identichnosti. (In Rus.)

12. Fuko, M. Use of pleasures. History of sexuality. SPb: Akadem. proekt, 2004. V. 2. (In Rus.)

13. Khitruk, E. B. Gender intersection as a factor in the denaturation of gender differences in Deidra McCloskey's theory. Web. 05.01.2020. https://www.researchgate.net/publication/324600302_Gendernoe_ peresecenie_kak_faktor_denaturalizacii_polovyh_razlicij_v_teorii_Dejdry_Makkloski (In Rus.)

14. Khitruk, E. B. Strategies for the denaturation of the categories "masculine" and "feminine" in modern philosophy. Dr. philos. sci. diss. Tomsk, 2018. (In Rus.)

15. Ashmore, R. D., Sewell A. D. Sex/Gender and the Individual. Web. 05.01.2020. https://www.link. springer.com/chapter/10.1007 \%2F978-1-4419-8580-4_16. (In Engl.)

16. Klysing, A. Exposure to Scientific Explanations for Gender Differences Influences Individuals' Personal Theories of Gender and Their Evaluations of a Discriminatory Situation. Sex Roles, no. 5-6, pp. 253-265, Web. 05.01.2020. https://www.link.springer.com/article/10.1007/s11199-019-01060-w (In Engl.)

17. Money, J. and Ehrhardt, A. A. Man and woman, boy and girl: Differentiation and dimorphism of gender identity from conception to maturity. Johns Hopkins U. Press. 1972. (In Engl.)

Received: February 8, 2020; accepted for publication February 28, 2020

\section{Information about author}

Subbotina Nadezhda D., Doctor of Philosophy, Professor, Transbaikal State University; 30 AleksandroZavodskaya st., Chita, 672039, Russia; e-mail: dialectica@yandex.ru; https://orcid.org/0000-0003-3251-4076.

\section{Reference to the article}

Subbotina N. D. Are the Concepts of "Essence of a Woman" and "Essence of a Man" Out of Date? // Humanitarian Vector. 2020. Vol. 15, No. 2. PP. 43-53. DOI: 10.21209/1996-7853-2020-15-2-43-53. 